\section{Commentary: Ross procedure is indeed a safe and durable option for critical aortic valve disease in neonates and infants}

\author{
Osami Honjo, MD, PhD
}

Management of neonates and infants with critical aortic valve stenosis (AS) poses a significant challenge. The patients present with various degree of left ventricular dysfunction and endocardial fibroelastosis due to critical downstream obstruction, secondary pulmonary hypertension, and important additional lesions such as mitral valve dysplasia and aortic arch obstruction. Balloon aortic valvuloplasty has been a standard first intervention for these patients, but surgical intervention is needed when balloon valvuloplasty is ineffective or results in significant aortic insufficiency (AI). Ross/Ross-Konno procedure is an effective surgical treatment for those neonates and infants with residual critical AS or developed significant AI, but is associated with relatively high mortality and morbidities, especially among patients who have aortic arch obstruction and/ or mitral valve disease, severe left ventricular dysfunction, or require an emergency or urgent Ross procedure due to hemodynamic instability. ${ }^{1}$

Laxford and colleagues ${ }^{2}$ from The Children's Hospital at Westmead report their institutional experiences of Ross/Ross-Konno procedure spanning more than 2 decades. They report no early mortality and only 1 late mortality among 35 neonates $(\mathrm{n}=13)$ and infants $(\mathrm{n}=22)$. This is a shockingly excellent outcome for patients who have so many high-risk anatomic and physiological features. The first hurdle is to execute

From the Division of Cardiovascular Surgery, Labatt Family Heart Centre, The Hospital for Sick Children, Toronto, Ontario, Canada; and Department of Surgery, University of Toronto, Toronto, Ontario, Canada.

Disclosures: The author reported no conflicts of interest.

The Journal policy requires editors and reviewers to disclose conflicts of interest and to decline handling or reviewing manuscripts for which they may have a conflict of interest. The editors and reviewers of this article have no conflicts of interest.

Received for publication July 25, 2021; revisions received July 25, 2021; accepted for publication July 26, 2021; available ahead of print Aug 3, 2021.

Address for reprints: Osami Honjo, MD, PhD, Division of Cardiovascular Surgery, Labatt Family Heart Center, The Hospital for Sick Children, 555 University Ave, Toronto, ON M5G1X8 Canada (E-mail: osami.honjo@sickkids.ca).

J Thorac Cardiovasc Surg 2022;163:376-7 $0022-5223 / \$ 36.00$

Copyright $₫ 2021$ Published by Elsevier Inc. on behalf of The American Association for Thoracic Surgery

https://doi.org/10.1016/j.jtcvs.2021.07.044

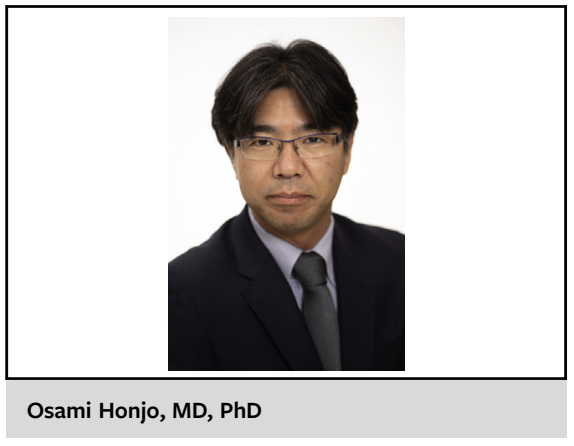

CENTRAL MESSAGE

Luxford and colleagues report excellent early and late outcomes of Ross/Ross-Konno procedure in neonates and infants, including preserved neoaortic valve function and geometry.

Ross/Ross-Konno procedure without any major residual anatomic lesions. The majority of the patients in their series had trivial or mild neo-AI. Only 1 patient required concomitant mitral valve repair-a low prevalence compared with other clinical series that may be partly associated with this excellent survival because we all know significant mitral valve disease in this population is an Achilles' heel. The second hurdle is to effectively support a dysfunctional left ventricle after Ross/Ross-Konno procedures. The combination of preexisting left ventricular dysfunction and/or endocardial fibroelastosis and prolonged cardiopulmonary bypass time poses a scenario of significant postoperative left ventricular dysfunction. Six $(17 \%)$ patients required postoperative mechanical circulatory support, but all of them were weaned from support at a mean duration of 4.7 days. In our institution, we sometimes employ a hybrid procedure (bilateral pulmonary artery banding and ductal stenting) as an interim procedure for patients with critical AS and severely reduced left ventricular function. Lastly, the authors report no reintervention to the neoaortic valve during the follow-up period and 1 patient required surgical reintervention for left ventricular outflow tract. The neoaortic valve remains competent in the vast majority of the patients and neoaortic valve $z$ score remains constant at the final follow-up, which is consistent with other series. ${ }^{3}$ 
This excellent clinical report is very encouraging for all of us who treat this critically ill patient cohort. The report emphasizes that early technical success leads to excellent early and late outcomes. I am particularly encouraged by the fact that all patients who needed mechanical support postoperatively were able to be weaned. Only 1 subgroup is missing from this report: The group with significant mitral valve disease, who remain a high-risk group with less-optimal options and outcomes.

\section{References}

1. Shinkawa T, Bove EL, Hirsch JC, Devaney EJ, Ohye RG. Intermediate-term results of the Ross procedure in neonates and infants. Ann Thorac Surg. 2010;89: 1827-32.

2. Laxford JC, Ayer JG, Betts K, Salve GG, Orr Y, Chard RB, et al. The Ross/RossKonno procedure in infancy is a safe and durable solution for aortic stenosis. $J$ Thorac Cardiovasc Surg. 2022;163:365-75.

3. Pasquali SK, Cohen MS, Shera D, Wernovsky G, Spray TL, Marino BS. The relationship between neo-aortic root dilation, insufficiency, and reintervention following the Ross procedure in infants, children, and young adults. J Am Coll Cardiol. 2007;49:1806-12.
See Article page 365 .

\section{Commentary: Ross procedure in neonates and infants: Withstanding the litmus test of time}

Manan Desai, MD, ${ }^{\mathrm{a}}$ Michael Ma, MD, ${ }^{\mathrm{a}}$ and Can Yerebakan, $\mathrm{MD}^{\mathrm{b}}$

More than 50 years after Donald Nixon Ross developed his eponymous procedure of replacing a diseased aortic valve with pulmonary autograft, the technique has become an established surgical option for aortic valve replacement. ${ }^{1}$ The Ross procedure offers superior hemodynamic parameters in comparison to alternative means for aortic valve replacement, avoidance of anticoagulation therapy, and growth potential for patients at younger ages. In the pediatric population, it is the sole option if valve repair is not feasible or fails. The main disadvantages of the Ross procedure are autograft failure primarily in the form of neoaortic root dilatation and an almost definite need for reintervention on both valves down the line.

\footnotetext{
From the ${ }^{a}$ Department of Cardiothoracic Surgery, Lucile Packard Children's Hospital, Stanford University, Palo Alto, Calif; and ${ }^{\mathrm{b}}$ Division of Cardiovascular Surgery, Children's National Hospital, George Washington University School of Medicine and Health Sciences, Washington, DC.

Disclosures: The authors reported no conflicts of interest.

The Journal policy requires editors and reviewers to disclose conflicts of interest and to decline handling or reviewing manuscripts for which they may have a conflict of interest. The editors and reviewers of this article have no conflicts of interest.

Received for publication Oct 4, 2021; revisions received Oct 4, 2021; accepted for publication Oct 4, 2021; available ahead of print Oct 7, 2021.

Address for reprints: Can Yerebakan, MD, Division of Cardiovascular Surgery, Children's National Hospital, George Washington University School of Medicine and Health Sciences, Washington, DC (E-mail: cyerebakan@childrensnational.org). J Thorac Cardiovasc Surg 2022;163:377-8 $0022-5223 / \$ 36.00$

Copyright $(2021$ by The American Association for Thoracic Surgery https://doi.org/10.1016/j.jtcvs.2021.10.004
}

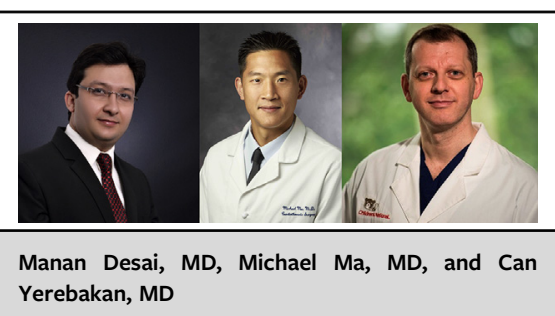

CENTRAL MESSAGE

Ross procedure in infants and neonates entails high initial morbidity. However, the longterm outcomes are good, with an acceptable, but definite risk of reintervention(s).

Luxford and colleagues ${ }^{2}$ have shared their excellent results of the Ross/Ross-Konno procedure in patients younger than age 1 year. We congratulate the authors for their outstanding results that should encourage us to utilize the technique more often in pediatric populations. In other series, the average early mortality of the Ross procedure in infants varies from $7 \%$ to $27 \%$. $^{3-6}$ In this retrospective analysis of 35 patients, there was no surgical mortality. Therefore, we have the privilege to comment on a study with among the best early surgical results for Ross/Ross-Konno in infants and neonates. Strikingly, $60 \%$ of all patients underwent emergency procedures; all of the 13 neonates had an emergency repair. Morbidity was high: use of extracorporeal membrane oxygenation $(17 \%)$, delayed sternal closure $(70 \%)$, and incidence of low cardiac output $(60 \%)$. There are other notable aspects of this study. Compared with previous studies, fewer patients 